\title{
Atrial Arrhythmias in Adults with Repaired Congenital Heart Disease
}

\author{
Shahnawaz Amdani ${ }^{1}$ and Peter P. Karpawich ${ }^{2 *}$ \\ ${ }^{1}$ Section of Cardiology, The Carmen and Ann Adams Department of Pediatrics, The Children's Hospital of Michigan \\ Wayne State University School of Medicine, USA \\ ${ }^{2}$ Director, Cardiac Electrophysiology, The Children's Hospital of Michigan, Wayne State University School of Medicine, USA
}

Received: September 02, 2015; Accepted: October 03, 2015; Published: October 05, 2015

*Corresponding author: Peter P. Karpawich, Director, Cardiac Electrophysiology, The Children's Hospital of Michigan, 3901 Beaubien Blvd, Detroit, MI 48201, Tel:+ 313-745-5481; E-mail: pkarpawi@dmc.org

\begin{abstract}
With advances in surgical and medical care over the past several decades, there has been a marked improvement in survival such that over $90 \%$ of children with Congenital Heart Disease (CHD) in developed countries today are expected to survive into adulthood. At present there are currently over 1 million adults with repaired congenital heart in the United States alone, over 100,000 in Canada, and 1.8 million in Europe. However, repaired congenital heart does not equate to a normal heart. In spite of excellent techniques, surgical repairs often left behind prosthetic materials and scars which often became the nidus for reentrant arrhythmias, especially atrial. Although sinus node dysfunction and resultant atrial flutter/ fibrillation become evident in the elderly, comparable atrial arrhythmias will occur among younger ACHD patients often in their second and third decades of life, and can range from asymptomatic to hemodynamically significant and potentially lethal. In the long term, arrhythmias are a leading cause of morbidity and mortality in adults with repaired CHD. This review discusses current approaches to atrial arrhythmia identification and management among ACHD patients.
\end{abstract}

\section{Introduction}

Due to advances in medical/surgical cardiac care, over $90 \%$ of children born with Congenital Heart Disease (CHD) in developed countries today are expected to survive into adulthood [1]. At present, population-based studies have found that there are currently over 1 million adults with CHD (ACHD) in the United States alone, over 100,000 in Canada, and 1.8 million in Europe [2-4].

Arrhythmias increase in prevalence with increasing age in the vulnerable ACHD population and are among the most common causes for hospital admission and mortality among these patients [5-7]. They may present as brady- or tachyarrhythmias or both. With certain repaired congenital heart defects being associated with an increased incidence simply due to inherent anatomy [8]. With improving patient survival, health care delivery focus has shifted from early determinants of morbidity and mortality, such as the complexity of congenital heart lesions and associated surgical risk factors (prematurity, genetic syndromes, etc) to late predictors of morbidity and mortality associated with systemic ventricular dysfunction, heart failure, hemodynamic alterations, early coronary artery disease, hepatic dysfunction and malignancy and arrhythmias.

\section{Arrhythmia Burden in Repaired Congenital Heart}

Bradyarrhythmias are most commonly occurring due to sinus or AV nodal dysfunction, often due to surgical cannulation for bypass performed during infancy or septal defect repairs. Certain CHD, such as atrial septal defects, can be associated with intrinsic sinus node dysfunction, while repaired CHD (Mustard/Senning procedures for D-Transposition of The Great Arteries (D-TGA)) carry an increased sinus node dysfunction burden due to the extensive surgical manipulations associated with the intra-atrial baffle required to re-route venous blood flow to the pulmonary ventricle $[9,10]$. Other defects, such as congenitally-corrected TGA (often referred as CC-TGA, L-TGA, ventricular inversion), Atrioventricular Canals (AVC), primum atrial septal defects and ventricular septal defects may intrinsically have abnormalities with AV node/bundle of His conduction due to an inferiorly and posteriorly displaced AV node and a hypoplastic left anterior fascicle. L-TGA is associated with late-onset complete AV block while patients with AVC defects or tricuspid atresia may exhibit a leftward or superior frontal plane QRS axis. Repair of any septal defect can impair AV node conduction. This can be evident either immediately following repair or present years later due to the encroachment of fibrotic tissue on the conduction pathways. Any right ventriculotomy incision can transect the moderator band and cause a distal Right Bundle Branch Block (RBBB) pattern. The combination of a "left or superior axis" with associated RBBB pattern on a surface ECG, therefore, does not always indicate progressive conduction abnormalities associated with coronary disease but may be the simple consequence of an inherently altered QRS axis due to the underlying anatomy with a clinicallyinnocent distal RBBB pattern in a patient with a repaired CHD defect, and need not be a concern for coronary artery intervention (Figure 1). 
More than $50 \%$ of patients with repaired congenital heart disease can develop atrial tachyarrhythmias by the age of 65 years [8]. These arrhythmias may be mediated by scars, accessory pathways (especially in Ebstein's anomaly of the tricuspid valve), $\mathrm{AV}$ node reentry, twin AV nodes (L-TGA), macro-reentrant circuits, automatic foci, or non-automatic foci $[10,11]$. Atrial reentry is the most common tachyarrhythmia among ACHD patients. Also the prevalence of atrial fibrillation increases as the ACHD population ages. The risk of late sudden death for patients surviving operations for common congenital heart defects is 25 to 100 times greater than an age-matched control population [6]. Fortunately, the absolute incidence of these devastating events remains relatively low, at approximately $0.1 \%$ per year.

In addition to direct effects on the conduction tissue and surgical scars, atrial arrhythmias among ACHD patients can be the result of mechanical considerations including post-operative pressure and volume overload, resulting in stretched atrial chambers. This is of special consideration among patients with single ventricle physiology in whom variations of the surgical "Fontan" atrial-pulmonary connection techniques result in elevated atrial pressure, often to $20 \mathrm{mmHg}$. Separation of atrial muscle by fibrotic tissue predisposes to reentrant arrhythmias. A slow form of atrial flutter, Intra-Atrial Reentrant Tachycardia (IART) is commonly seen among such patients (Figure 2) and, due to the thickness of the atrial tissue, difficult to control by drug or ablation therapies $[12,13]$. Since it is beyond the scope of this review, a detailed description of ACHD arrhythmias including typical ECG features associated with repaired CHD can be found in the recent publication by the Pacing and Clinical Electrophysiology Society [12]. An abbreviated listing of ECGs among the more common repaired congenital heart defects can be found in table 1.

\section{Arrhythmia Identification}

\section{Non-invasive Testing}

Electrocardiogram: It is extremely important to understand "expected" ECG findings in adults with different repaired/ unrepaired congenital heart defects so as not to make an erroneous diagnosis. Also understanding the natural course of different lesions will give the interpreter an advantage as to what arrhythmias are more common in different heart lesions. Special note must be made of the heart rate (atrial flutter from incisonal tachycardia/scars in ACHD patients tend to be at a slower rate and have different $p$ wave morphology that classic flutter waves), $\mathrm{AV}$ and intraventricular conduction disturbances, QRS duration, repolarization pattern and atrial/ventricular ectopics all of which may be useful to identify different rhythm abnormalities (Figure 3).

Even in the absence of symptoms, a screening ECG is useful to diagnose certain electrophysiological abnormalities. For example, among patients with Ebstein's anomaly there is

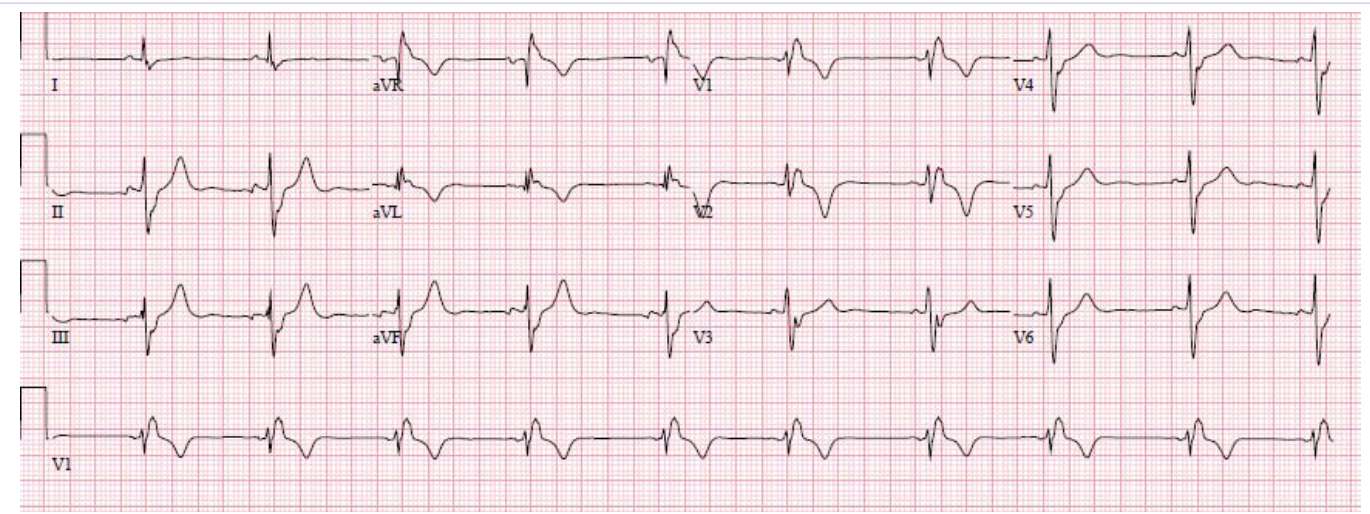

Figure 1: Typical ECG appearance of a postoperative patient with repaired AV canal, illustrating a left axis with right bundle branch block pattern. Typically, current computer-generated ECG interpretations will erroneously indicate bifascicular block often leading to inappropriate coronary artery studies or pacemaker implant.

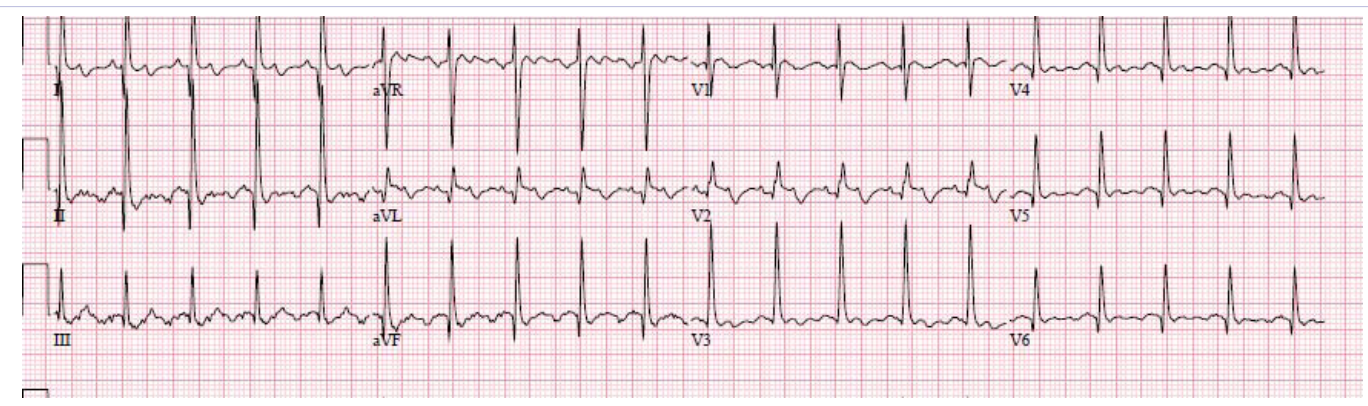

Figure 2: ECG showing IART with an atrial rate of $188 \mathrm{bpm}$ and 2:1 AV conduction in a patient with repaired complex CHD consisting of TGA with dextrocardia. IART can be misinterpreted as sinus tachycardia. Clinical correlation is often required to make the correct diagnosis. 
Table 1: Frequently seen post-surgical ECG features of common congenital heart defects.

\begin{tabular}{|l|l|l|l|}
\hline Congenital Defect & PR interval & QRS axis & QRS pattern \\
\hline ASD-2 & 1 & Normal, rightward & Normal or LAD \\
\hline VSD & Normal or $1^{\circ}$ AVB & LAD & Normal or RBBB \\
\hline AVC & $1^{\circ}$ AVB & Normal or RAD & rSr \\
\hline TOF & normal & RAD & RBBB \\
\hline D-TGA (atrial baffle) & normal & RVH \\
\hline
\end{tabular}

ASD-2 : Atrial Septal Defect secundum type; AVB: Atrioventricular Block; AVC: Atrioventricular Canal; D-TGA: D-Transposition of Great Arteries; iRBBB: Incomplete Right Bundle Branch Block; LAD: Leftward Axis Deviation; TOF: Tetralogy Of Fallot; RAD: Rightward Axis Deviation; RVH: Right Ventricular Hypertrophy

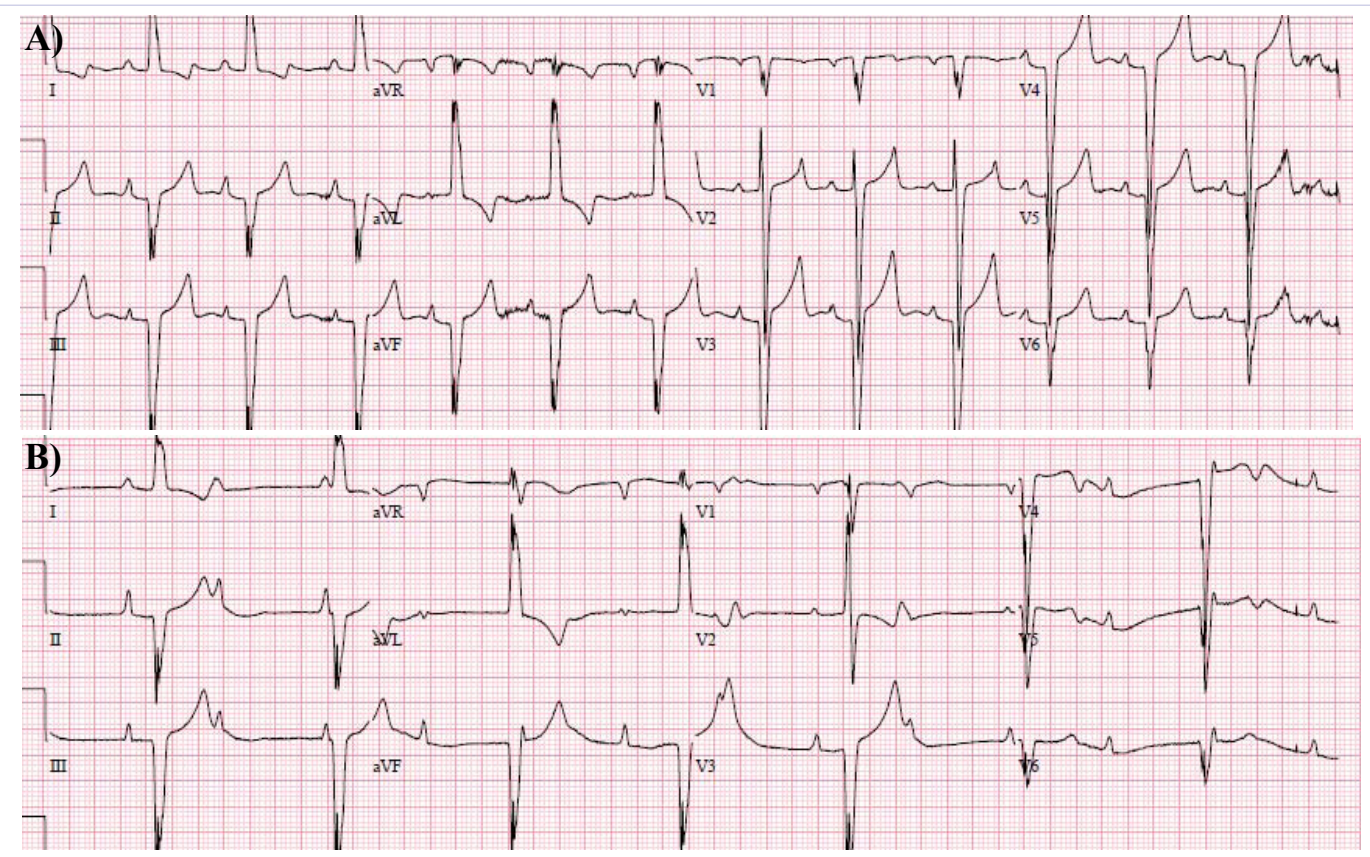

Figure 3: ECG showing progression from 1o (A) to complete AV block (B) in a patient with L-TGA as well as sinus dysfunction requiring pacemaker implant. The intrinsic ECG illustrates an abnormal leftward axis, intraventricular conduction delay and atypical $Q$ waves. There was no coronary artery disease.

an increased prevalence of Wolff-Parkinson-White accessory connections. Among patients with repaired Tetralogy of Fallot, the rate of QRS duration change over time has a correlation with right ventricular size and propensity for tachycardia and sudden death $[14,15]$. An ECG plays an important role in monitoring patients on antiarrhythmic medications and other QT-prolonging drugs. Among patients with pacemakers, it is a good surveillance tool to assess pacemaker functioning.

Holter/Event monitoring: Routine Holter monitoring every few years is an important element of surveillance in ACHD. In one study, among the patients without arrhythmias on ECG, 26\% had arrhythmias noted on Holter monitoring. Of the patients with multiple Holter monitoring performed, 34\% had a new arrhythmia noted on repeat monitoring [16]. Certain ACHD patients are at higher risk for arrhythmias/sudden death, such as those with D-TGA and atrial baffle repairs, aortic stenosis, Fontan palliation or after repair of Tetralogy of Fallot. Event recorders are important in evaluating sporadic symptoms. Most commonly used event recorders are a non-invasive type but in cases where there is a high suspicion for malignant arrhythmias with no yield on non-invasive event monitoring an implantable loop recorder may be considered.

Exercise stress testing: Cardiopulmonary exercise testing can be useful in adults with CHD and known or suspected exercise-induced arrhythmias in order to provoke the arrhythmia, establish a diagnosis, or assess response to therapy. It can provide information regarding sinus node behavior, AV conduction, and inducibility of tachyarrhythmias [17].

\section{Invasive Testing}

Intracardiac electrophysiology studies: Electrophysiology Study (EPS) is the most definitive means of characterizing arrhythmias in ACHD (location, mechanism etc.). Also, if a source of arrhythmia is identified, ablation procedures could ostensibly be performed to help eliminate the source of such arrhythmias. EPS may pose unique challenges in ACHD. Vascular access 
may be complicated by associated vascular anomalies or prior interventions and hence venography should be considered. Due to occluded or interrupted veins, alternative vascular routes such as internal jugular, subclavian, or transhepatic may be attempted. Ablation outcomes are different between patients with normal anatomy vs. CHD with post repair anatomy, altered hemodynamic, and residual prosthetic materials adding to lesseffective ablative results. For example atrial tachycardias among patients with Tetralogy of Fallot, single ventricle with variation of the "Fontan" atriopulmonary connections or intra-atrial baffle (Mustard/Senning) repair may only exhibit only a 70\% success compared with the over $90 \%$ success among patients with normal and non-surgical repair anatomy [18-20].

Hemodynamic catheterization: Since altered pressures/ volumes can contribute to arrhythmias, adults with repaired CHD and new-onset or worsening arrhythmias, should undergo hemodynamic assessment to determine the need for any intervention, such as pulmonary valve repair. Coronary evaluation is important in ACHD with higher risk of coronary ischemia such as congenital anomalies of the coronary arteries, coronary arteriovenous fistulae, a history of surgery involving coronary arteries (D-TGA with the arterial switch (Jatene procedure)), or the potential for coronary compression by vascular conduits or stents [12].

\section{Treatment Options for Arrhythmia Eradication}

\section{Ablation therapies}

The prevalence of late post operative atrial tachycardias varies and the most common mechanism is macro reentry within the atrial musculature, so-called intra-atrial reenterant tachycardia (IART) often due to cavotricuspid isthmusdependent (counterclockwise or clockwise) flutter or scarbased macro reentry. Anatomic structures, areas of scar tissue, suture lines, cannulation sites, or surgically inserted prosthetic materials often form the boundaries of these reentrant circuits. Although pharmacotherapies can help control some abnormal rhythms, the ultimate therapeutic goal should entail attempts at arrhythmia substrate ablation [12]. A 3-dimensional electroanatomic mapping system is useful to guide catheter ablation of postoperative atrial tachyarrhythmias in adults with CHD [21]. Reported acute procedural success rates range from $72 \%$ to $77 \%$, depending in part on the complexity of the underlying defects. However, recurrences can be as high as 54\% [22]. Due to atrial wall thickness associated with some ACHD defects ("Fontan"), transcatheter ablation may not be as effective as surgical techniques such as the various modifications of the Cox-Maze procedure.

The Society of Thoracic Surgeons 2011 database that included 5265 adults with CHD operated on over 9 years, demonstrated a $20 \%$ combined incidence of concurrent and primary arrhythmia surgery, including pacemaker implantation [23]. In the ACHD surgical population, arrhythmias were the most common preoperative factor and postoperative complication. Patients undergoing Fontan revision or conversion had the highest incidence of pre-operative arrhythmia, noted in $53 \%$, followed by $16 \%$ in those having mitral valvuloplasty. When open heart cardiac surgery is planned for an adult with CHD it is recommended that the individual undergo a thorough arrhythmia assessment to determine if any additional surgical interventions are required.

\section{Implantable Cardiac Device Therapy}

Permanent Pacing: Indications are well-established for patients with symptomatic brady- as well as tachyarrhythmias depending if atrial, ventricular or both chambers are involved [12]. Prior to device implantation, it is critical that the implanting physician have a thorough and accurate understanding of the congenital heart defect and cardiothoracic surgical procedure(s) performed. Meticulous attention should be given to previous operative reports, noninvasive imaging, and angiography. A detailed understanding of the venous drainage, baffles, conduits, and any residual shunts should be sought prior to implantation to avoid patient morbidities during attempted device implant [24]. It is now well recognized that right ventricular pacing, especially the apical and free wall regions, can have adverse effects on left ventricular function. Although ventricular septal pacing has been advocated as preferential to the apex, any surgical patch materials can negate the efficacy of that site. Recent studies from patients with and without CHD suggest that systemic left ventricular function is best preserved by first determining the most optimal pacing site based on paced-contractility response, prior to lead implant $[25,26]$.

Since inappropriate defibrillation shocks can frequently occur due to device oversensing, proper programming to discriminate between sinus tachycardia and other arrhythmias is mandatory when individualizing device therapies [27].

\section{Conclusions}

Adult congenital heart patients constitute a growing and challenging population. The presence of intrinsic congenital heart anatomies, in addition to surgical interventions, predisposes these patients to atrial arrhythmias beyond the scope of simple aging. Arrhythmia management will often be difficult. It behooves any and all healthcare providers to become acquainted with the various nuances of cardiac anatomy and surgical procedures involved, in order to provide effective and optimal patient care.

\section{References}

1. Khairy P, Ionescu-Ittu R, Mackie AS, Abrahamowicz M, Pilote L, Marelli AJ. Changing mortality in congenital heart disease. J Am Coll Cardiol. 2010; 56(14): 1149-57. doi: 10.1016/j.jacc.2010.03.085.

2. Marelli AJ, Mackie AS, Ionescu-Ittu R, Rahme E, Pilote L. Congenital heart disease in the general population: changing prevalence and age distribution. Circulation. 2007; 115(2): 163-72.

3. Moons P, Engelfriet P, Kaemmerer H, Meijboom FJ, Oechslin E, Mulder BJ, et al. Delivery of car for adult patients with congenital heart disease in Europe: results from the Euro Heart Survey. Eur Heart J. 2006; 27(11): 1324-30.

4. Go AS, Mozaffarian D, Roger VL, Benjamin EJ, Berry JD, Borden WB, et al. Heart disease and stroke statistics-2013 update: are port from the American Heart Association. Circulation. 2013; 127(1): e6-e245. 


\section{doi: 10.1161/CIR.0b013e31828124ad.}

5. Kaemmerer H, Bauer U, Pensl U, Oechslin E, Gravenhorst V, Franke $A$, et al. Management of emergencies in adults with congenital cardiac disease. Am J Cardiol. 2008; 101(4): 521-5. doi: 10.1016/j. amjcard.2007.09.110.

6. Nieminen HP, Jokinen EV, Sairanen HI. Causes of late deaths after pediatric cardiac surgery: a population-based study. J Am Coll Cardiol. 2007; 50(13): 1263-71.

7. Verheugt CL, Uiterwaal CS, vanderVelde ET, Meijboom FJ, Pieper PG, van Dijk AP, et al. Mortality in adult congenital heart disease. Eur Heart J. 2010; 31(10): 1220-9. doi: 10.1093/eurheartj/ehq032.

8. Bouchardy J, Therrien J, Pilote L, Ionescu-Ittu R, Martucci G, Bottega $\mathrm{N}$, et al. Atrial arrhythmias in adults with congenital heart disease. Circulation. 2009; 120(17): 1679-86. doi: 10.1161/ CIRCULATIONAHA.109.866319.

9. Karpawich PP, Antillon JR, Cappola PR, Agarwal KC. Pre- and Postoperative Electrophysiologic Assessment of Children with Secundum Atrial Septal Defect. Am J Cardiol. 1985; 55(5): 519-21.

10. Bouchardy J, Therrien J, Pilote L, Ionescu-Ittu R, Martucci G, Bottega $\mathrm{N}$, et al. Atrial arrhythmias in adults with congenital heart disease. Circulation. 2009; 120(17): 1679-86. doi: 10.1161/ CIRCULATIONAHA.109.866319.

11. Epstein MR, Saul JP, Weindling SN, Triedman JK, Walsh EP Atrioventricular reciprocating tachycardia involving twin atrioventricular nodes in patients with complex congenital heart disease. J Cardiovasc Electrophysiol. 2001; 12(6): 671-9.

12. Khairy P, Van Hare GF, Balaji S, Berul CI, Cecchin F, Cohen MI, et al PACES/HRS Expert Consensus Statement on the Recognition and Management of Arrhythmias in Adult Congenital Heart Disease: developed in partnership between the Pediatric and Congenital Electrophysiology Society (PACES) and the Heart Rhythm Society (HRS). Endorsed by the governing bodies of PACES, HRS, the American College of Cardiology (ACC), the American Heart Association (AHA), the European Heart Rhythm Association (EHRA), the Canadian Heart Rhythm Society (CHRS), and the International Society for Adult Congenital Heart Disease (ISACHD). Heart Rhythm. 2014; 11(10): e102-65. doi: 10.1016/j.hrthm.2014.05.009.

13. Balaji S, Johnson TB, Sade RM, Case CL, Gillette PC. Management of atrial flutter after the Fontan procedure. J Am Coll Cardiol. 1994; 23(5): 1209-15.

14. Gatzoulis MA, Till JA, Somerville J, Redington AN. Mechanoelectrical interaction in tetralogy of Fallot.QRSprolongation relates to right ventricular size and predicts malignant ventricular arrhythmias and sudden death. Circulation. 1995; 92(2): 231-7.

15. Arya S, Kovach J, Singh H, Karpawich PP. Arrhythmias and Sudden Death Among Older Children and Young Adults Folllowing Tetralogy of Fallot Repair in the Current Era: Are Previously-Reported Risk Factors Still Applicable? Congenit Heart Dis. 2014; 9(5): 407-14. doi: 10.1111/chd.12153.
16. Rodriguez FH, Moodie DS, Neeland M, Adams GJ, SnyderCS. Identifying arrhythmias in adults with congenital heart disease by24-h ambulatory electrocardiography. Pediatr Cardiol. 2012; 33(4): 591-5. doi: 10.1007/s00246-012-0183-1.

17.Zartner PA, Toussaint-Goetz N, Photiadis J, Wiebe W, Schneider MB. Telemonitoring with implantable electronic devices in young patients with congenital heart diseases. Europace. 2012; 14(7): 1030-7. doi: 10.1093/europace/eur434.

18. Khairy P, Landzberg MJ, Gatzoulis MA, Lucron H, Lambert J, Marcon F, et al. Value of programmed ventricular stimulation after tetralogy of Fallot repair: a multicenter study. Circulation. 2004; 109(16): 19942000.

19. Betts TR, Roberts PR, Allen SA, Salmon AP, Keeton BR, Haw MP, et al. Electrophysiological mapping and ablation of intra-atrial reentry tachycardia after Fontan surgery with use of a noncontact mapping system. Circulation. 2000; 102(4): 419-25.

20. Kanter RJ, Papagiannis J, Carboni MP, Ungerleider RM, Sanders WE, Wharton M. Radiofrequency catheter ablation of supraventricular tachycardia substrates after Mustard and Senning operations for d-transposition of the great arteries. J Am Coll Cardiol. 2000; 35(2): 428-41.

21. De Groot NM, Kuijper AF, Blom NA, Bootsma M, Schalij MJ. Threedimensional distribution of bipolar atrial electrogram voltages in patients with congenital heart disease. Pacing Clin Electrophysiol. 2001; 24 (9 Pt 1): 1334-42.

22. Triedman JK, Alexander ME, Love BA, Collins KK, Berul CI, Bevilacqua $\mathrm{LM}$, et al. Influence of patient factors and ablative technologies on outcomes of radiofrequency ablation of intraatrial re-entrant tachycardia in patients with congenital heart disease. J Am Coll Cardiol. 2002; 39(11): 1827-35.

23. Mascio CE, Pasquali SK, Jacobs JP, Jacobs ML, Austin EH 3rd. Outcomes in adult congenital heart surgery: analysis of the Society of Thoracic Surgeons database. J Thorac Cardiovasc Surg. 2011; 142(5): 1090-7. doi: 10.1016/j.jtcvs.2011.07.028.

24. Mond $\mathrm{H}$ and Karpawich PP. Pacing Options in the Adult Patient with Congenital Heart Disease. Massachusetts: Blackwell-Futura Publishing, Inc. Malden; 2007.

25. Karpawich PP, Singh H, Zelin K. Optimizing paced ventricular function in patients with and without repaired congenital heart disease by contractility-guided pacing lead implant Pacing Clin Electrophysiol. 2015; 38(1): 54-62. doi: 10.1111/pace.12521.

26. Karpawich PP. Improving pacemaker therapy in congenital heart disease: contractility and resynchronization. Semin Thorac Cardiovasc Surg Pediatr Card Surg Annu. 2015; 18(1): 51-6. doi: 10.1053/j.pcsu.2014.12.002.

27. Berul CI, Van Hare GF, Kertesz NJ, Dubin AM, Cecchin F, Collins KK, et al. Results of a multicenter retrospective implantable cardioverterdefibrillator registry of pediatric and congenital heart disease patients. J Am Coll Cardiol. 2008; 51(17): 1685-91. doi: 10.1016/j. jacc.2008.01.033. 